Disclosure of Interests: None declared

DOI: 10.1136/annrheumdis-2019-eular.7489

\section{AB0523 MENOPAUSE IN AN EGYPTIAN COHORT OF SYSTEMIC LUPUS ERYTHEMATOSUS PATIENTS: EFFECT OF THE DISEASE}

Samah A. Elbakry, Safaa A. Hussein, Rasha M. Hamouda, Marina W. Naguib. Internal Medicine Department, Division of Rheumatology, Ain Shams University, Cairo, Egypt

Background: Systemic lupus erythematosus (SLE) is a chronic systemic autoimmune disease that mainly affects females in the reproductive age ${ }^{1}$. Although SLE generally emerges during reproductive ages, it was found that lupus patients experience menopause at younger age than the general population; however, whether the occurrence of menopause at a younger age in lupus patients results from the gonadotoxic effects of Cyclophosphamide treatment or from an autoimmune-mediated ovarian injury is debated ${ }^{2}$

Objectives: To identify menopause characteristics in an Egyptian cohort of women with SLE with effect of the disease on menopausal symptoms and the characteristics of disease activity and disease damage in perimenopausal and post-menopausal patients.

Methods: In this cross-sectional observational study, data of 120 consecutive SLE female patients who fulfilled the 2012 ACR/SLICC criteria $^{3}$, above the age of 35 . Disease activity was assessed by using the SLE disease activity index (SLEDAI) ${ }^{4}$, and accumulated damage was assessed by Systemic Lupus International Collaborative Clinics/American College of Rheumatology Damage Index (SLICC/ACR DI) ${ }^{5}$. Laboratory assessment was done to all patients including follicle stimulating hormone (FSH) and luteinizing hormone (LH) blood levels.

Results: The mean age of the patients was $45.067 \pm 8.211$ years and median disease duration was $5.074 \pm 5.567$ years $(\min 0.08-\max 21$ years). It was found that the mean of total SLEDAI score was $4.667 \pm$ 3.537 and mean of total SLICC/ACR damage index was $0.633 \pm 0.819$. Of 120 patients $20 \%$ had premature menopause, $29.17 \%$ had natural menopause and $50.83 \%$ were still menstruating (table 1). It was found that the age at menopause (either natural or premature menopause) ranged from 26 to 54 years with the mean $45.170 \pm 7.278$ years. There was a statistically significant negative correlation between $\mathrm{LH}$ and total SLEDAI $(r=-0.178, P=0.052)$. It was also found a statistically significant positive correlation between FSH and cumulative Cyclophosphamide dose $(r=0.440, P<0.001)$ and between $\mathrm{LH}$ and cumulative Cyclophosphamide dose $(r=0.214, P=0.046)$ (table 2$)$.

Table 1. Menstrual status:

\begin{tabular}{lcc}
\hline & \multicolumn{2}{c}{ Positive } \\
\cline { 2 - 3 } & $\mathrm{N}$ & $\%$ \\
\hline Premature & 24 & 20.00 \\
menopause & & \\
Natural menopause & 35 & 29.17 \\
Menstruating & 61 & 50.83 \\
\hline
\end{tabular}

Conclusion: SLE has a reproductive and hormonal impact on female patients, either because of disease activity or due to pharmacological adverse effects. The mean age at menopause (either natural or premature menopause) is 45 years. High $\mathrm{LH}$ is associated with lower disease activity. High cumulative Cyclophosphamide dose is associated with high $\mathrm{FSH}$ and $\mathrm{LH}$.

\section{REFERENCES}

[1] Mills JA. Systemic lupus erythematosus. New Engl J Med 1994; 330: 1871-1879.

[2] Sammaritano LR. Menopause in patients with autoimmune diseases. Autoimmun Rev. 2012; 11(6-7).

[3] Petri M., Orbai AM., Alarcón GS, et al. Derivation and Validation of the Systemic Lupus International Collaborating Clinics Classification Criteria for Systemic Lupus Erythematosus. Arthritis Rheum. 2012; 64: 2677-86.

[4] Bombardier C, Gladman D, Urowitz M, et al. Derivation of the SLEDAI. A disease activity index for lupus patients. The Committee on Prognosis Studies in SLE. Arthritis Rheum 1992, 35, 630-640.

[5] Gladman D, Ginzler E, GoldsmithC, et al. The development and initial validation of the Systemic Lupus International Collaborating Clinics/American College of Rheumatology damage index for systemic lupus erythematosus. Arthritis Rheum. 1996; 39: 363-369.
Table 2. Correlation study between FSH \& LH and Cyclophosphamide:

\begin{tabular}{|c|c|c|c|c|}
\hline \multicolumn{5}{|l|}{ Correlations } \\
\hline & \multicolumn{2}{|c|}{$\mathrm{FSH}(\mathrm{mlU} / \mathrm{ml})$} & \multicolumn{2}{|c|}{$\mathrm{LH}(\mathrm{mlU} / \mathrm{ml})$} \\
\hline$\overline{\mathrm{R}}$ & $\begin{array}{c}\mathrm{P}- \\
\text { value }\end{array}$ & $\bar{R}$ & $\begin{array}{c}P_{-} \\
\text {value }\end{array}$ & \\
\hline Cumulative & 0.440 & $<$ & 0.214 & $0.046^{*}$ \\
\hline $\begin{array}{l}\text { Cyclophosphamide } \\
\text { (mg) }\end{array}$ & & $0.001^{*}$ & & \\
\hline
\end{tabular}

Disclosure of Interests: None declared

DOI: 10.1136/annrheumdis-2019-eular.1226

\section{AB0524 BIOMARKERS IN SYSTEMIC LUPUS ERYTHEMATOSUS (SLE): A PROSPECTIVE FOLLOW-UP STUDY}

Selma Sarı ${ }^{1}$, Suzan Çınar ${ }^{2}$, Bahar Artim-Esen ${ }^{3}$, Ahmet Gul $^{3}$, Mahdume Lale Ocal ${ }^{3}$, Gunnur Deniz ${ }^{2}$, Murat Inanc ${ }^{3} .{ }^{1}$ Istanbul University, Istanbul Faculty of Medicine, Internal Medicine, Istanbul, Turkey; ${ }^{2}$ Istanbul University, Aziz Sancar Institute of Experimental Medicine, Immunology, Istanbul, Turkey, ${ }^{3}$ Istanbul University, Istanbul Faculty of Medicine, Rheumatology, Istanbul, Turkey

Background: BAFF and APRIL are cytokines involved in B cell development and they take place in the pathogenesis of SLE.

Objectives: The aim of this study was to investigate the relationship between serum BAFF/APRIL levels with clinical features and disease activity in SLE patients.

Methods: We included 79 patients with SLE (ACR criteria) and 27 healthy controls into the study. Serum BAFF and APRIL levels were assessed by ELISA. In 19 patients with active disease at the time of the assessment BAFF/APRIL levels were reassessed at least 6 months later (mean 7.8 months) and disease activity was evaluated by SLEDAI. New renal involvement was observed in 16 patients during the study and renal involvement was previously detected in 12 patients.

Results: Although both BAFF (median 0.7 vs $0.41 \mathrm{ng} / \mathrm{ml}$ ) and APRIL (median 2.3 vs $1.05 \mathrm{ng} / \mathrm{ml}$ )levels were higher in patients with SLE compared to the control group ( $p<0.001$ ), no correlation was found between BAFF/APRIL levels and SLEDAI scores. Only 9 patients (11.4\%) had both BAFF and APRIL in normal range (95\% confidence interval). When patients were grouped according to disease activity as no activity (SLEDAl $=0$ ), low disease activity and active disease, there was no difference in BAFF/APRIL levels between groups. Serum BAFF levels were higher in patients with renal disease activity (median $0.94 \mathrm{ng} / \mathrm{ml}$ vs 0.61 $\mathrm{ng} / \mathrm{ml}, \mathrm{p}=0,01)$, and there was a positive correlation between APRIL levels and proteinuria $(r=0.42, p=0,02)$. There was no association between BAFF/APRIL levels and anti-dsDNA positivity but a weak inverse correlation was observed between BAFF and $C 3$ levels $(r=0.25, P=0.02)$. No correlation was found between BAFF/APRIL levels and renal SLEDAI score, renal histopathology activity and chronicity index scores. In the active disease group after follow-up, there was no significant change in BAFF (from 1,63 ng/ml to $1,2 \mathrm{ng} / \mathrm{ml}$ ) and APRIL levels (from 2,11 ng/ml to $2,31 \mathrm{ng} / \mathrm{ml}$ ).

Conclusion: BAFF/APRIL levels were found to be significantly higher in patients with SLE compared to controls, but no association with disease activity was found. BAFF levels are correlated with decreased C3 levels. These results suggest that both cytokines are involved in the pathogenesis of SLE, and that serum BAFF and APRIL levels can be valuable as a biomarker in SLE especially in patients with renal activity. Long-term studies on the effect of treatment are needed.

Disclosure of Interests: None declared

DOI: 10.1136/annrheumdis-2019-eular.4671

\section{AB0525 ANTI-SMITH ANTIBODY IS ASSOCIATED WITH DISEASE ACTIVITY IN PATIENTS WITH NEW-ONSET SYSTEMIC LUPUS ERYTHEMATOSUS}

Seungmin Jung, Juyoung Yoo, Sungsoo Ahn, Sangwon Lee, Jason Jungsik Song, Yongbeom Park. Yonsei University College of Medicine, Internal Medicine, Seoul, Korea, Rep. of (South Korea)

Background: Anti-Smith (Sm) antibody is a highly specific antibody for systemic lupus erythematosus (SLE). Despite the remarkable specificity of anti-Sm antibodies for SLE, the association between anti-Sm antibody level and the clinical manifestation of SLE is still unclear.

Objectives: We aimed to evaluate the association between anti-Sm antibodies and disease activity in patients with new-onset SLE. 
Methods: We included patients who were repeatedly tested for anti-Sm antibodies at SLE diagnosis and within 12 months after SLE diagnosis The clinical and laboratory profiles, and SLE disease activity index (SLEDAI) were collected at the time of the anti-Sm antibody test. SLEDAI and laboratory variables associated with disease activity were compared at baseline between patients with and without anti-Sm antibodies. The longitudinal association between disease activity and anti-Sm antibodies was also evaluated in total patients and in those with anti-Sm antibodies. Results: Of 92 patients who were tested for anti-Sm antibodies at the time of SLE diagnosis, 67 and another 67 patients were followed up for the presence of anti-Sm antibodies at 6 and 12 months, respectively. Although the baseline SLEDAI was comparable in SLE patients with and without anti-Sm antibodies, the serum anti-Sm antibody level at diagnosis was significantly correlated with SLEDAI $(P=0.003)$. Patients with antiSm antibodies at 12 months had higher SLEDAI and anti-dsDNA levels than those without anti-Sm antibodies $(P=0.002$, respectively). The changes in anti-Sm antibody levels over 12 months were also correlated with the alterations in SLEDAI $(P=0.029)$.

Conclusion: This study suggests that anti-Sm antibody level is associated with disease activity in patients with new-onset SLE, and that monitoring of anti-Sm antibody levels could help assess the disease activity.

\section{REFERENCES}

[1] Migliorini, P., et al., Anti-Sm and anti-RNP antibodies. Autoimmunity, 2005. 38(1): p. 47-54.

[2] Clinical associations of anti-Smith antibodies in PROFILE: a multi-ethnic Iupus cohort. Clin Rheumatol, 2015. 34(7): p. 1217-23.

[3] What is the clinical significance of anti-Sm antibodies in systemic lupus erythematosus? A comparison with anti-dsDNA antibodies and C3. Clin Exp Rheumatol, 2017. 35(4): p. 598-606

Disclosure of Interests: None declared

DOI: 10.1136/annrheumdis-2019-eular.7016

\section{AB0526 PRIMARY SJOGREN'S SYNDROME AND ORGAN SYSTEM INVOLVEMENT: A RETROSPECTIVE STUDY OF 153 PATIENTS FROM WESTERN INDIA}

Girish Kakade, Piyush Joshi, Canchi Balakrishnan, Akash Khune. PD Hinduja National Hospital and Medical Research Centre, Rheumatology, Mumbai, India

Background: Primary Sjogren's syndrome (pSS) is under diagnosed and improperly treated disease because of its variable modes of presentation. Limited data is available on pSS from India.

Objectives: To describe organ system involvement in patients with pSS and compare to other studies.

Methods: Retrospective proforma based analysis of patients with pSS (AECG 2002 criteria) from 2002-2012 at a tertiary rheumatology centre was done. Demographic data and systemic organ involvement of patients was noted.

Results: We had 153 consecutive patients of pSS (135 females, 18 males) in the 10 years which were included. Mean age at diagnosis was $47 \pm 11.62$ years. Mean duration of sicca symptoms was $32( \pm 31)$ months prior to presentation. Organ system involvement was seen in $93(60.7 \%)$ patients as follows:- Musculoskeletal involvement in $90(58.8 \%)$ patients, Skin involvement in 48 (31\%) patients, Lung involvement in 27 (17.6\%) patients, Renal involvement in $22(14.3 \%)$ patients, Neurological involvement in $21(13.7 \%)$ patients, Gl involvement in $6(3.9 \%)$ patients and Lymphoma in $2(1.3 \%)$ patients. Comparison of organ system involvement with other major studies of pSS is shown in table 1 .

Table 1. Comparison with major studies of pSS from different populations:

\begin{tabular}{|c|c|c|c|c|c|}
\hline Parameter & $\begin{array}{c}\text { Spanish }^{1} \\
(1994-2007)\end{array}$ & Italian $^{2}$ & $\begin{array}{c}\text { Chinese }^{2} \\
(1985- \\
2006)\end{array}$ & $\begin{array}{c}\text { Vellore }^{2} \\
(2004- \\
2011)\end{array}$ & $\begin{array}{c}\begin{array}{c}\text { Our } \\
\text { study } \\
(2002- \\
2012)\end{array} \\
\end{array}$ \\
\hline Criteria used & $\begin{array}{l}\text { European } \\
\text { community }\end{array}$ & $\begin{array}{l}\text { European } \\
\text { community }\end{array}$ & AECG & $\begin{array}{c}\text { AECG } \\
\text { ACR }\end{array}$ & $\mathrm{AECG}$ \\
\hline No. of patients & 1010 & 1115 & 573 & 332 & 153 \\
\hline Females (\%) & 937 (93\%) & $1067(95.7)$ & $524(91.5)$ & $315(94.9)$ & $\begin{array}{c}135 \\
(88.2)\end{array}$ \\
\hline Mean age (yrs) & $53.8 \pm 0.5$ & $57.5 \pm 13.7$ & 39 & $44.5 \pm 10.6$ & $47 \pm 11.6$ \\
\hline $\begin{array}{l}\text { Disease duration } \\
\text { (months) }\end{array}$ & $74.9 \pm 4$ & 72 & - & $\begin{array}{c}62.6 \\
\pm 65.67\end{array}$ & $35 \pm 41$ \\
\hline Xerostomia (\%) & $975(96)$ & $1033(92.6)$ & $484(84.5)$ & $313(94.3)$ & $\begin{array}{c}146 \\
(95.4)\end{array}$ \\
\hline Xerophthalmia (\%) & $968(96)$ & $1054(94.5)$ & $401(70)$ & 295 (88.9) & $\begin{array}{c}148 \\
(96.7)\end{array}$ \\
\hline
\end{tabular}

4)

Conclusion: Indian pSS patients are younger than their European counterparts. Majority of these patients show organ system involvement. Raynaud's phenomenon is rare in Indian patients. Lung, renal and gastrointestinal involvement in Indian patients is more prevalent than in European patients, but less prevalent than in Chinese patients. Musculoskeletal and neurological involvement is similar across different populations.

\section{REFERENCES}

[1] Ramos-Casals M, Solans R, Rosas J, et al. GEMESS Study Group. Primary Sjögren syndrome in Spain: clinical and immunologic expression in 1010 patients. Medicine (Baltimore) 2008; 87: 210-9.

[2] Sandhya $P$, Jeyaseelan L, Scofield RH, Danda D. Clinical Characteristics and Outcome of Primary Sjogren's Syndrome: A Large Asian Indian Cohort. The Open Rheumatology Journal. 2015;9:36-45.

Disclosure of Interests: None declared DOI: 10.1136/annrheumdis-2019-eular.6399

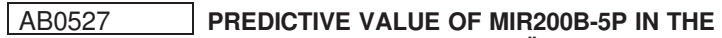 LYMPHOMAGENESIS IN SJÖGREN'S SYNDROME (SS): COMPARISON WITH THE PUBLISHED PREDICTION MODELS. PRELIMINARY RESULTS}

Efstathia Kapsogeorgou, Athanase Protogerou, Aristea Papageorgiou, Michael Voulgarelis, Athanasios Tzioufas. School of Medicine, National and Kapodistrian University of Athens, Pathophysiology, Athens, Greece

Background: miR200b-5p expression levels are decreased in the minor salivary glands of SS patients who have or will develop non-Hodgkin's lymphoma $(\mathrm{NHL})$, discriminate them from those who will not $(p<0.0001)$ and independently predicted $\mathrm{NHL}$ development $(\mathrm{p}<0.0001)^{1}$.

Objectives: To compare the predictive performance of low miR200b-5p levels with the previously published multifactorial predictive models.

Methods: 27 SS patients who didn't develop NHL during follow up (median follow up time upon biopsy performance, range: 8.9yrs, 1.33$14 \mathrm{yrs}$ ) and 17 diagnosed with $\mathrm{NHL}$ during follow up (pre-lymphoma, median follow-up till lymphoma diagnosis, range: 3.67yrs, 0.42-8.5yrs) were studied. The multifactorial predictive models examined were: 1 . Ioannidis et $\mathrm{al}^{2}$ who defined patients expressing at least one of low C4 levels, salivary gland enlargement (SGE) and purpura as high-risk, 2. Baimpa et $\mathrm{al}^{3}$ who designed 3 models (1, 2 and 3 ) based on the expression of at least 1,2 or $\geq 3$, respectively, of neutropenia, cryoglobulinemia, splenomegaly, lymphadenopathy and low C4 levels, 3. Quartuccio et $\mathrm{al}^{4}$ who identified as high risk patients those having SGE and at least two of the following: low C4 levels, cryoglobulinemia, anti-La antibodies and leukopenia, and 4. Fragkioudaki et $\mathrm{al}^{5}$ that defined as high-risk group those carrying $\geq 3$ of the independent risk factors including SGE, lymphadenopathy, Raynaud phenomenon, anti-Ro/SSA and/or anti-La/SSB antibodies, rheumatoid factor positivity, monoclonal gammopathy and low C4 levels. Analyses were performed by estimating the area under the ROC curve (AUC), Kaplan-Meier (KM) lymphoma-free survival curves 